\title{
Characterization of land subsidence in Tabriz basin (NW Iran) using InSAR and watershed analyses
}

\author{
Sadra Karimzadeh ${ }^{1}$
}

Received: 21 November 2014/ Accepted: 27 April 2015/Published online: 12 May 2015

(C) Akadémiai Kiadó 2015

\begin{abstract}
Iran as a semi-arid and arid country has a serious water challenge in the recent decades. While water demand is increasing, as a consequence, land subsidence due to excessive water extraction is happening in major basins of the country. Recently the land subsidence has been proposed as an environmental problem in the country and thus important projects on this matter have been conducted. For example several basins in the country have been studied using SAR data and their result had a great deal on water management section. This paper studies the large-scale immature land subsidence in the Tabriz basin (NW Iran) using the permanent scatterer synthetic aperture radar interferometry technique with the small baseline InSAR approach and watershed analysis. InSAR time series analysis of 17 Envisat advanced SAR images between 2003 and 2010 reveals three oval-shaped regions of subsidence. The recognized water wells in the study area are categorized into two groups (sub-basin 1 and 2) based on watershed analysis in the TB and are compared with InSAR results. InSAR time series from Kriging interpolation method are also compared with GPS time series of permanent TABZ station which suggests that the land subsidence only is growing in the basin far away from the Tabriz city.
\end{abstract}

Keywords Tabriz basin $\cdot$ Land subsidence $\cdot$ InSAR $\cdot$ Watershed

\section{Introduction}

Land subsidence is a major environmental problem in some countries as it can cause serious damages to the urban components such as: structures, buildings and sanitary sewers as a long-term deformation (Motagh et al. 2007; Dehghani et al. 2009; Osmanoğlu et al. 2011; Lubis et al. 2011; Rigo et al. 2013). It may occur due to various reasons such as

Sadra Karimzadeh

sadra.karimzadeh@gmail.com; s.karimzadeh@stu.kanazawa-u.ac.jp

1 Faculty of Environmental Design, Kanazawa University, Kanazawa, Japan 
earthquakes, mining, over extraction of oil, natural gas or groundwater and some urban activities (e.g. metro and tunnel constructions, etc.).

Precipitation rate and natural recharges in arid or semi-arid countries like Iran are relatively lower than the global average (Sedighi et al. 2010) which shows importance of underground waters for agricultural or industrial activities. Interest of Iranians for ground water extraction goes back more than thousands of years ago when the Qanat system was invented for steady water extraction. In Iran, Qanat system is a traditional underground tunnels excavated into the hillside which provides water demand for agriculture and population. In the recent decades the country is faced with serious challenges in the water sector. The accumulated water behind dams and underground water (Qanat) cannot rectify demand of industrial, agriculture and urban purposes (Madani 2014). Thus a large number of deep wells (>50 m depth) have been excavated in different parts of the study area (Razzaghmanesh et al. 2006).

Iran has six major hydrological basins as follows: (1) Persian Gulf basin, (2) Central basin, (3) Urmia basin, (4) Sarakhs basin, (5) Hamoon basin and (6) Khazar basin (Fig. 1). Almost half of the country's renewable water resources are located in the Persian Gulf basin which is about one fourth of the country's surface area. Central basin as the biggest

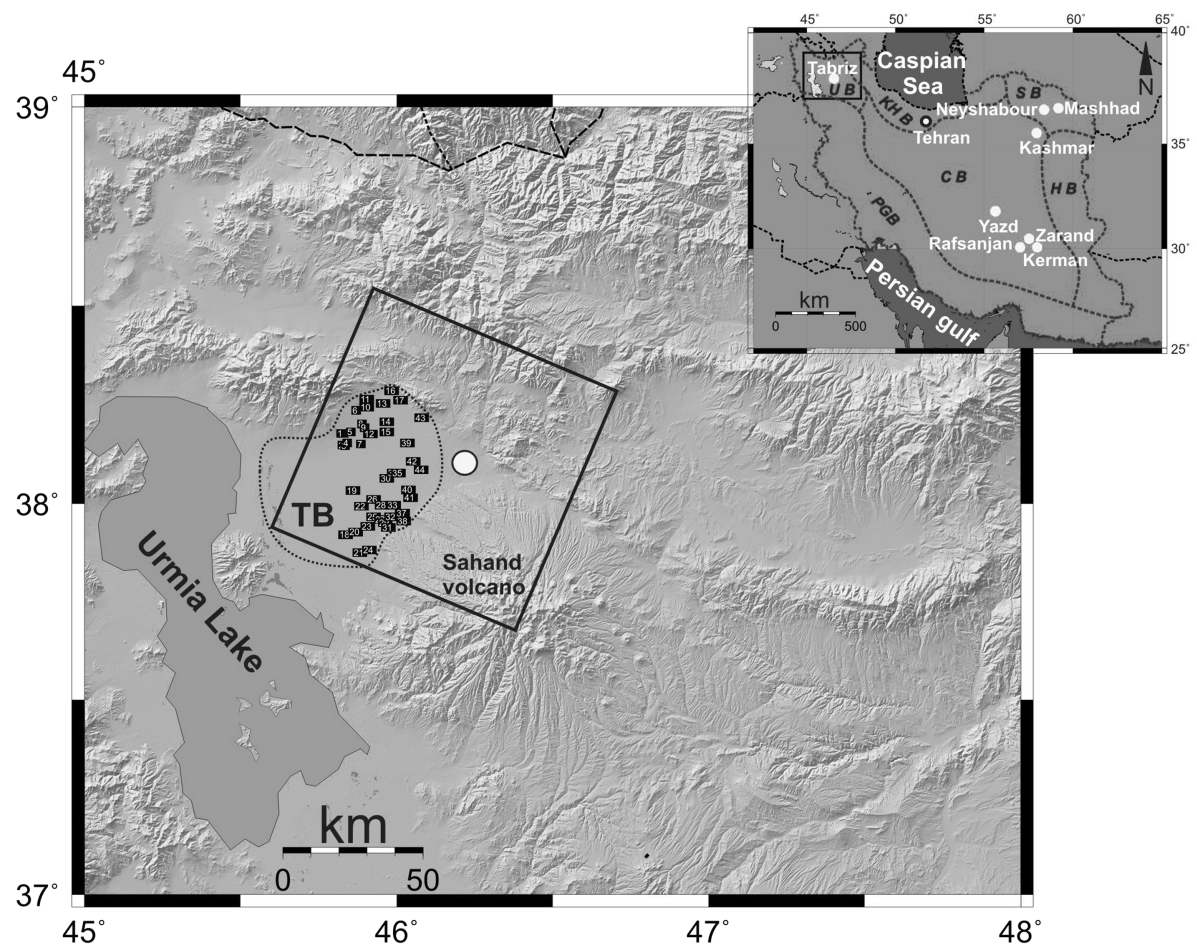

Fig. 1 Main figure map of NW Iran shaded by ASTER topography data with $30 \mathrm{~m}$ accuracy. The box $\left(100 \times 100 \mathrm{~km}^{2}\right)$ shows acquired radar images from descending orbits. The yellow circle indicates the city of Tabriz. Number labeled boxes show the location of the excavated wells in the Tabriz basin (TB). The dashed polygon shows TB's boundaries. Inset figure six major basins in Iran divided by the pink dashed polygons. PGB Persian Gulf basin; $U B$ Urmia basin; KHB Khazar basin; SB Sarakhs basin; $H B$ Hamoon basin; $C B$ Central basin. The yellow circles showing important cities subjected by land subsidence phenomenon. (Color figure online) 
basin in term of land area has less than one third of the renewable water resources (FAO 2009). Excessive water (or other fluids) withdrawals have caused land subsidence throughout the country (Alipour et al. 2008; Anderssohn et al. 2008; Dehghani et al. 2009; Motagh et al. 2007) due to pore fluid pressure decreasing between granules in unconsolidated sediments (weak materials) (Hoffmann and Zebker 2001; Bell et al. 2008). Balance of downfall and water extraction could be helpful to control or mitigate the probable hazards in the future (Motagh et al. 2007). In this study large-scale surface deformation is investigated using the synthetic aperture radar interferometry (InSAR) and piezometric data in the Tabriz basin $\left(\sim 3000 \mathrm{~km}^{2}\right)$ which is a sub-basin of Urmia basin located between $37^{\circ} 57^{\prime} \mathrm{N}-38^{\circ} 20^{\prime} \mathrm{N}$ and $45^{\circ} 39^{\prime} \mathrm{E}-46^{\circ} 20^{\prime} \mathrm{E}$. The Tabriz basin (TB) is located in the west of Lake Urmia and from the east its boundaries are limited by the city of Tabriz (Fig. 1). The investigated area contains various structures (mostly Quaternary alluvium) from different ages (Devonian to Quaternary) because of a marine regression happened in the Pliocene period, as well as a turning into a continental condition. The Plio-Pleistocene indicated volcanic activities, with lava flows in the southern part of the Tabriz basin. Thus, the Sahand volcano engrossed the southern part of the Tabriz city. This mountain is surrounded by volcanic sediments and alluvial tuffs which cover marls and sandstones of below layers. These volcanic tuffs are enlarged in a vast area $\left(\sim 1000 \mathrm{~km}^{2}\right)$ and overlie the Pliocene beds of the TB (Moghaddam and Najib 2006).

Some important industrial structures, such as thermal power plant, petrochemical center and Tabriz-Miandoab water lifeline are situated in the TB and more than 40 wells have been excavated to extract groundwater for agriculture and industrial needs (e.g. cooling major components of the thermal power plant which supplies the electricity of NW Iran). Furthermore, statistical studies show that water-extraction rate in the TB is about 5 million $\mathrm{m}^{3}$ per year while the allowable threshold is around $3 \mathrm{~m}^{3}$ for each year (Razzaghmanesh et al. 2006).

In Iran, different InSAR strategies have taken into account in order to detect the land subsidence in the major basins. Alipour et al. (2008) studied the land subsidence of Tehran plain using 46 Envisat ASAR data obtained in the descending (Track 378 and 419) and ascending (Track 414) orbits between 2003 and 2007. Motagh et al. (2007) studied Mashhad land subsidence (in Sarakhs basin) through a pool of Envisat images between 2003 and 2005 using a conventional (stacked method) InSAR method to compare the obtained results with the measurements from precise land leveling. Follwing Akbari and Motagh (2011) suggested a weighted least square (WLS) method for the same region which is based on an appropriate combination of differential interferograms produced by image pairs with a small baseline (orbital separation) in order to limit the spatial decorrelation phenomena. Dehghani et al. (2009) produced InSAR time series through 14 Envisat ASAR (2004-2006) data and a small baseline method (SBAS) for a small historical city Neyshabour subjected to land subsidence again in Sarakhs basin. Anderssohn et al. (2008) used a total of 22 Envisat ASAR data for the time interval from July 2003 to March 2006 in the descending satellite track 435 using conventional InSAR to study land subsidence in Kashmar valley in Hamoon basin (for details see Table 1). In this study, immature land subsidence in the TB is investiagted using persistent scatterer synthetic aperture radar interferometry technique (PS-InSAR) combined with the small baseline InSAR (SBI) to construct the InSAR time series in a region of $10,000 \mathrm{~km}^{2}$. The study area is ideal for InSAR studies due to its arid and semi arid climate and its sparse vegetation would not be an obstacle for phase interferometry analysis. 
Table 1 Subsidence rate deduced through InSAR technique in some cities of Iran (see Fig. 1 for their location)

\begin{tabular}{|c|c|c|c|c|}
\hline Region & $\begin{array}{l}\text { Cumulative } \\
\text { subsidence } \\
\text { amount } \\
(\mathrm{cm})\end{array}$ & Period (years) & InSAR approach & Reference \\
\hline Mashhad & 30 & 2003-2005 & Conventional stacking & Motagh et al. (2007) \\
\hline Mashhad & 86 & 2004-2007 & WLS adjustment & $\begin{array}{l}\text { Akbari and Motagh, } \\
\text { (2011) }\end{array}$ \\
\hline Tehran & 45 & 2003-2007 & Conventional time series & Alipour et al. (2008) \\
\hline Neyshabour & 19 & 2004-2005 & SBAS & Dehghani et al. (2009) \\
\hline Rafsanjan & 19 & $\begin{array}{r}\text { May 2005- } \\
\text { July } 2005\end{array}$ & Conventional & Motagh et al. (2008) \\
\hline Kashmar & 6 & $\begin{array}{l}\text { Apr 2005- } \\
\text { July } 2005\end{array}$ & Conventional & Anderssohn et al. (2008) \\
\hline Kerman-Zarand & 20 & 2003-2004 & Conventional & Motagh et al. (2008) \\
\hline Yazd & 9 & 2003-2004 & Conventional & Motagh et al. (2008) \\
\hline
\end{tabular}

\section{SAR data and analysis}

InSAR had a long way to become a widely used technique to study surface deformations. Now it is recognized as a sophisticated technique of space geodesy to measure surface displacements in different aspects, especially its high sensitivity for vertical deformations and wide spatial coverage, makes easier to study on land subsidence phenomenon.

ASAR SLC (Single Look Complex) images from a descending orbit (T49), I2 swath mode, collected by Envisat satellite of European Space Agency (ESA) between May 2003 and January 2010 have been used (Table 2). Width and length of the obtained data frame are $100 \mathrm{~km}$ which covers major parts of the TB (see Fig. 1). Image with the orbit number of 27,157 is used as a master image. Small baseline of the interferometric pairs is an effective factor to increase quality of PS, hence one "single master" image with the shortest baselines relative to the other images is selected. Processes have been done using StaMPS/MTI (Hooper et al. 2010) which emphasis on DORIS computer code (Hanssen 2001; Kampes and Usai 1999) and focusing step is skipped, since the modality of the obtained images is SLC. Although conventional D-InSAR is a suitable approach to obtain good results for coseismic studies, but its temporal decorrelation, particularly in areas with dense and tall vegetation has a disadvantage for long term phenomena like land subsidence (Hu et al. 2014). StaMPS/MTI is a multi temporal InSAR technique to measure deformation signals through identifying the persistent scatterers (PS) so that the amount of the obtained PS can specify how much the PS-InSAR technique is successful (see details in Hooper et al. 2010). Simply put, discrimination of coherent and incoherent radar signal is the core idea behind PS-InSAR which means that an individual recognized PS has an interpretable characteristic in time (Sousa et al. 2011). StaMPS benefits amplitude dispersion index (ADI) to identify a bunch of pixels that includes all of the PS pixels. The ADI is defined by Ferretti et al. (2001) as follow: 
Table 2 List of the obtained SAR data (L1), their acquisition date, perpendicular baseline with respect to the master image and mean coherence values

\begin{tabular}{lrlllllll}
\hline $\begin{array}{l}\text { Image } \\
\text { no. }\end{array}$ & Orbit & Year & Month & Day & $\begin{array}{l}\text { Perp. } \\
\text { baseline }(\mathrm{m})\end{array}$ & $\begin{array}{l}\text { Period } \\
\text { (day) }\end{array}$ & $\begin{array}{l}\text { Classification } \\
\text { of image }\end{array}$ & $\begin{array}{l}\text { Mean } \\
\text { coherence }\end{array}$ \\
\hline 1 & 6115 & 2003 & 05 & 02 & 1540.1 & -1470 & Useless & - \\
2 & 6616 & 2003 & 06 & 06 & -721.6 & -1435 & Useless & - \\
3 & 8620 & 2003 & 10 & 24 & 826.3 & -1295 & Useless & - \\
4 & 9121 & 2003 & 11 & 28 & 159.5 & -1260 & Slave & 0.4212 \\
5 & 10,123 & 2004 & 02 & 06 & 41.2 & -1190 & Slave & 0.4491 \\
6 & 11,125 & 2004 & 04 & 16 & 349.5 & -1120 & Slave & 0.3774 \\
7 & 11,626 & 2004 & 05 & 21 & 384.6 & -1085 & Slave & 0.3611 \\
8 & 14,131 & 2004 & 11 & 12 & 634.5 & -910 & Slave & 0.3243 \\
9 & 20,143 & 2006 & 01 & 06 & 496.3 & -490 & Slave & 0.3610 \\
10 & 20,644 & 2006 & 02 & 10 & 384.1 & -455 & Slave & 0.3615 \\
11 & 25,153 & 2006 & 12 & 22 & 431.3 & -140 & Slave & 0.4207 \\
12 & 25,654 & 2007 & 01 & 26 & -352 & -105 & Slave & 0.4404 \\
13 & 26,155 & 2007 & 03 & 02 & 383.3 & -70 & Slave & 0.4747 \\
14 & 26,656 & 2007 & 04 & 06 & -153.7 & -35 & Slave & 0.4808 \\
15 & 27,157 & 2007 & 05 & 11 & 0 & 0 & Master & - \\
16 & 32,167 & 2008 & 04 & 25 & -84.6 & 350 & Slave & 0.4885 \\
17 & 39,181 & 2009 & 08 & 28 & 420.7 & 840 & Slave & 0.4198 \\
18 & 40,183 & 2009 & 11 & 06 & 344.9 & 910 & Slave & 0.4170 \\
19 & 40,684 & 2009 & 12 & 11 & -400.2 & 945 & Slave & 0.4003 \\
20 & 41,185 & 2010 & 01 & 15 & 191.6 & 980 & Slave & 0.4120 \\
\hline & & & & & & & &
\end{tabular}

$$
D_{A}=\frac{\sigma_{A}}{\mu_{A}}
$$

where $\sigma_{A}$ is standard deviation and $\mu_{A}$ is mean amplitude value. The value of ADI is typically 0.4 , but it could be assumed between 0.4 and 0.42 for PS selection and elimination of decorrelated pixels in vegetated areas (Ferretti et al. 2001; Sousa et al. 2011). Here, ADI is assumed to be 0.42 and the scene is subdivided into 25 patches with 200 and 1000 overlapping pixels in the range and azimuth directions respectively. StaMPS also finds and uses slowly decorrelating filtered phase pixels (SDFP) along with persistent scatterers (PS). Combination of these methods increases the number of selected points, accordingly, the number of stable points candidates (SP $=$ PS + SDFP) increases with increasing ADI value. Although the larger ADI values increases the number of PS candidates, but it also could lead to more unreliable points.

Using the combination of PS-InSAR and Small Baseline, sixteen interferograms are derived from a pool of 17 ASAR images with respect to their small baselines near $400 \mathrm{~m}$ and also before PS processing step, coherence threshold is assumed to be greater than 0.3 (Table 2). Three of the images (Nos. 1, 2 and 3) are not used in the PS processing. Their too long perpendicular baseline and temporal baseline could drastically affect the quality of the results as a function of the coherence. Topographic phase component contained within 


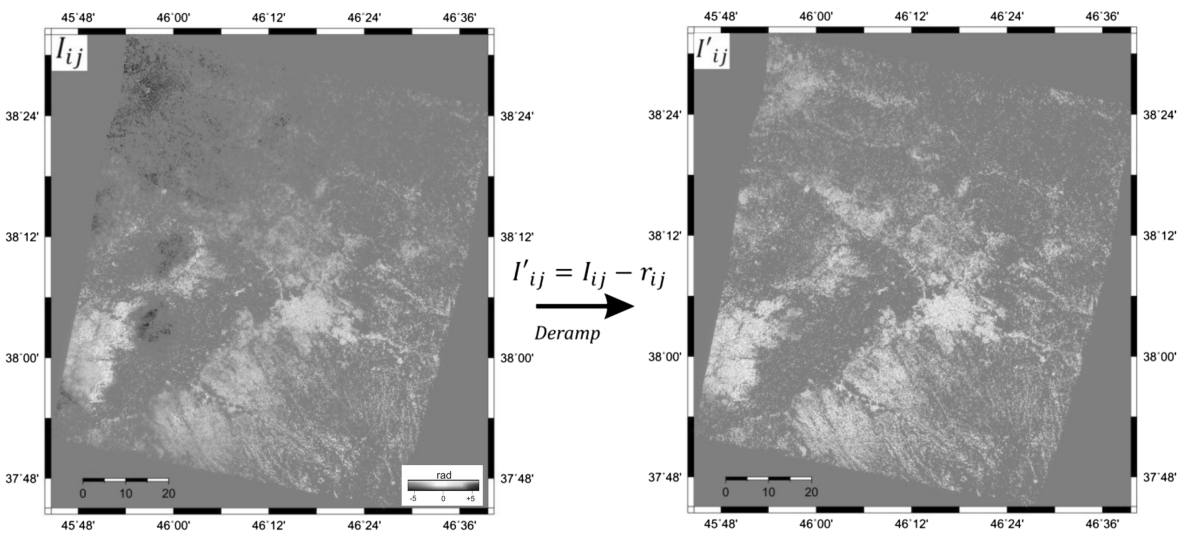

Fig. 2 An example of deramp procedure. Left is an interferogram of Tabriz region, contaminated by orbital errors with a linear ramp from red to blue (east to west). Right is the same interferogram after removing remained orbital errors. (Color figure online)

the interferograms is removed using an ASTER (http://jspacesystems.or.jp/ersdac/GDEM/) digital elevation model with spatial resolution about $30 \mathrm{~m}(\sim 1 \operatorname{arc} \mathrm{s})$ (Freemantle and Muller 2010). Precise orbit data (VOR_DOR) have been converted to delft orbit data (ODR) using a matlab code for estimating exact position of the satellite, but usually our estimation is imperfect, because the orbital error is not completely removed. The most popular method to solve this issue is the subtraction of an estimated linear trend (or phase ramp) from the interferogram. By fitting a linear plane to the interferograms, deramp value of the each interferogram is determined. Each Interferogram $\left(I_{i j}\right)$ is comprised of a master image $(i)$ and a slave image $(j)$ in a specific epoch, including an orbital phase ramp $\left(r_{i j}\right)$ which is based on the position error in the same epoch. The orbital errors can be assumed as contributing a phase ramp (Eq. 2), in a specific epoch. Thus, the phase ramp in the interferogram $I_{i j}$ is the difference between the phase ramps between period of $i$ and $j$ (Eq. 3). Accordingly $r_{i j}$ is determinable by fitting a linear plane to $I_{i j}$ and use these planes to determine the coefficients $a, b, c$ at each epoch. These are then used to calculate and remove an orbital phase ramp from each interferogram $\left(I_{i j}^{\prime}\right)$ (Fig. 2).

$$
\begin{gathered}
r_{i j}=a_{i} x+b_{i} y+c_{i} \\
r_{i j}=r_{i}-r_{j}=\left(a_{i}-a_{j}\right) x+\left(b_{i}-b_{j}\right) y+\left(c_{i}-c_{j}\right)
\end{gathered}
$$

\section{Methods and results}

\subsection{Ground water and watershed transform}

An aquifer system is an interbedded, saturated and made up of different parts that expresses as two forms of permeable (aquifer) and impermeable (aquitard). Drops in groundwater 
levels caused some bearers for the bulked material to move from under pressure pore to the granular skeleton of an aquifer system, resulting land subsidence. On the contrary, recharging aquifer leads to increase in pore pressure thereby causing ground uplift ( $\mathrm{Lu}$ and Danskin 2001). Lack of proper water recharging of wells and irregular water withdrawal are two main factors of aquifer system compaction in Iran (Dehghani et al. 2009; Motagh et al. 2008). Although, seasonal aquifer recharge in NW Iran is higher than the rest of Central Iran, the NW has undergone subsidence due to excessive ground water extraction over the last decades (Sedighi et al. 2010 and Moghtased-Azar et al. 2012). There are probably hundreds of illegal deep wells used mainly for agricultural purposes in the region. In this study over 40 deep wells are recognized and plotted in Fig. 3, but information of these wells are mostly lacking. Only piezometric measurements of the six wells $(1,3,5,15$, 26 and 30) are collected monthly by the Regional Water Organization. Water level measurement with a piezometer is based on liquid pressure above a specific datum. For
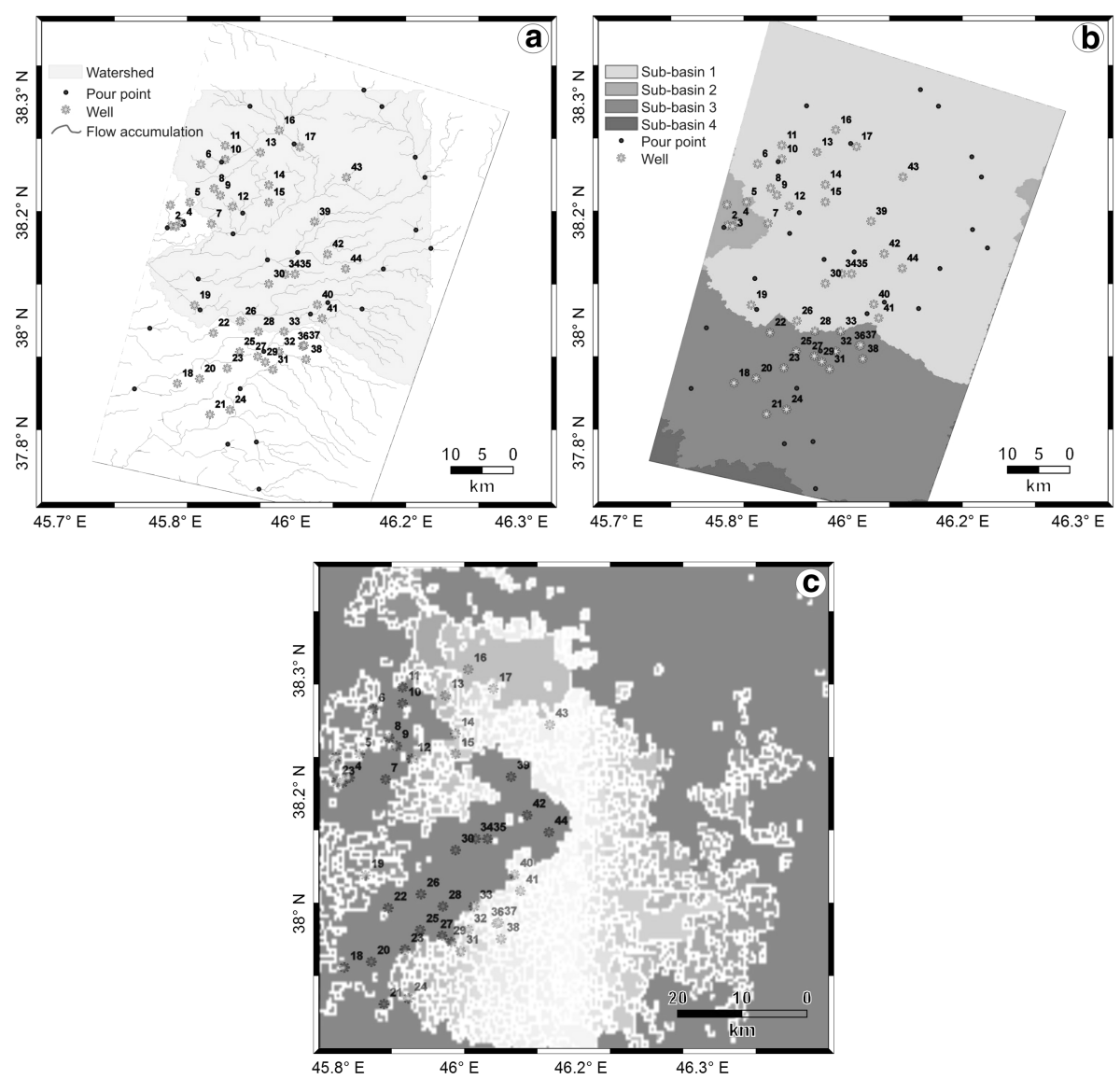

Fig. 3 a Water accumulation map of TB derived from ASTER digital elevation model. Blue polygon shows major watershed of the study area, $\mathbf{b}$ sub-basins in TB based on flow accumulation map and pour points (blue points), c watershed transform of subsidence area using InSAR velocities. White lines are watershed ridge lines. (Color figure online) 
example, in a washing machine, the height of the water in the tub is measured indirectly by measuring the pressure at the bottom of the tub. Accordingly in an aquifer, piezometric measurements also can be calculated from screen depth and piezometer's elevation.

In order to delineate the study area, a sophisticated image segmentation method is proposed (Akbarimehr et al. 2013). Having adequate and reasonable classes of the wells needs a watershed transform analysis. A watershed is the ridge (or upper slope) area that flow (i.e. water) goes to a pour area like a drainage basin. As already discussed, it can be part of a larger watershed and can also contain sub-watersheds (e.g. Tabriz basin as a subbasin of Urmia basin). In this paper watersheds are delineated through an ASTER digital elevation model in a couple of steps as follows:

At the first step the flow direction which is the steepest downslope neighbor of each pixel is calculated in the study area. Then in the second step, flow accumulation is calculated. In fact, flow accumulation is the accumulated weight of all pixels traveling into each downslope cell. The results came from the second step would be helpful in the third step to find some arbitrary pour points. The pour point, is a point on the surface at which water flows out of an area (e.g. a river mouth) and typically it could be the lowest point in a sub-basin or whatever is defined as a boundary. After snapping these points by the flow accumulated map, at the fourth step watershed areas can be calculated as shown in Fig. 3a and $b$. It must be noted that a threshold value (number of pixels that make a stream) should be specified at the fourth step.

As an alternative, another watershed transform method is carried out using InSAR results (subsidence patterns). The subsidence patterns are considered as raster images, in order to find "catchment basins" and "watershed lines". Unlike the previous watershed analysis which was done using a DEM, in this method, the analysis is carried out using InSAR velocities as the independent variables. The analysis starts with subsidence patterns which "belong together". This is called image segmentation, the process of separating objects from the background, as well as from each. The contrast color values can be assumed as catchment basins and watershed lines. This method (segmentation) usually gives us one watershed region for each local minimum value (or regional minimum) and watershed ridge line in the image (Fig. 3c). Although this method could be useful for delineation of subsidence patterns, but in this study for classification of the boreholes, the first method of watershed analysis is selected because the water level at each borehole is associated with surface waters and flow accumulation, in other words aquifers get water from precipitation (rain and snow) and they can also receive water from surface waters which is directly related with topographical watershed analysis.

The wells are classified into two groups based on above-mentioned sophisticated segmentation method which classifies sub-basins based on amount of accumulated water at each sub-basin. Sub-basin 1: wells 15, 26 and 30 which show significant subsidence in the core of the subsidence patterns. Sub-basin 2: wells of 1, 3 and 5 which do not show sensible deformation located in the outside margins of the subsidence patterns. Normally, the sub-basin 1 and 4 have minimum and maximum amount of water accumulation due to general slope of the region from NE to SW. This usually can be one of the reasons of higher water level in the wells of sub-basin 2 than sub-basin 1.

\subsection{InSAR and water level results}

Results from InSAR indicate that over 100,000 SP velocities have been recorded and the land subsidence patterns at the TB are emerging at three oval-shaped patterns in the subbasin 1 near the W15, W26 and W30 (Fig. 4). The all InSAR velocities should be 


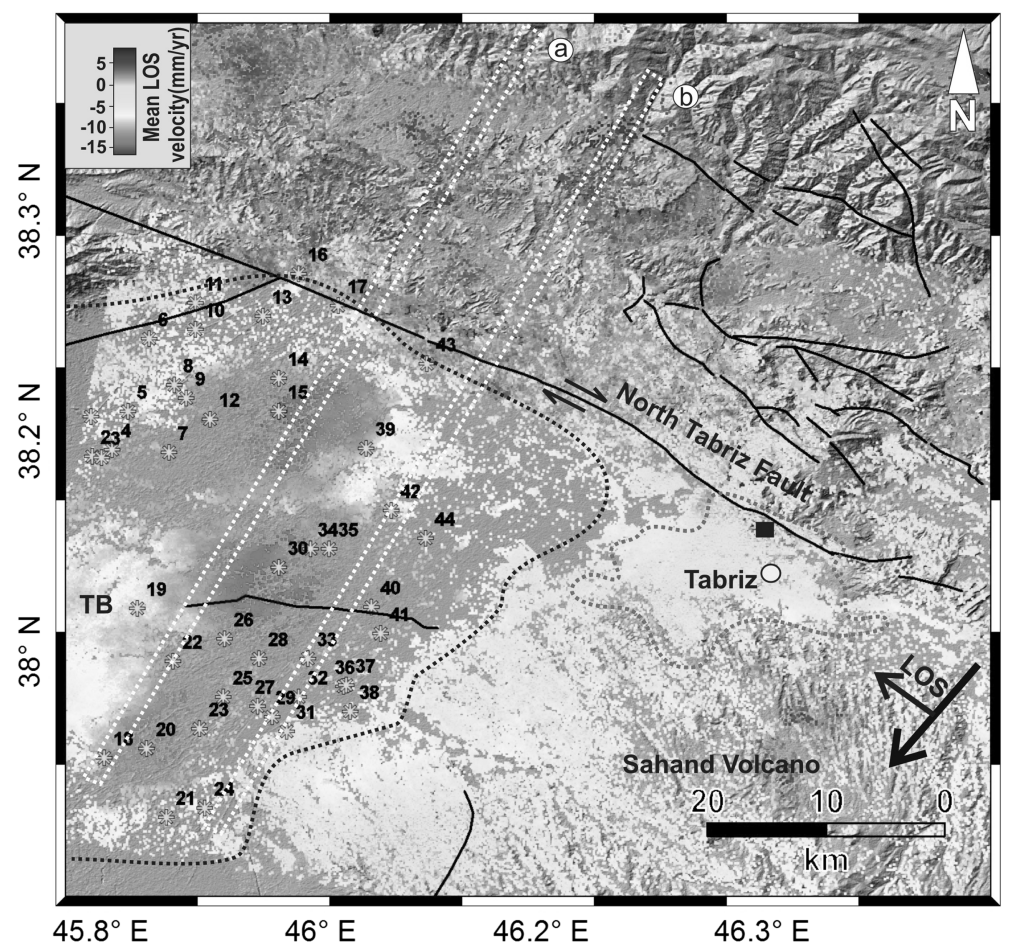

Fig. 4 Mean LOS subsidence rate between 2003 and 2010 in the Tabriz basin (TB) plotted on ASTER shaded relief image with the location of wells (green stars), and active faults (black lines). The black rectangle represents the zero deformation point. The dashed black and red polygons indicate Tabriz basin and Tabriz city respectively. The yellow circle is the location of GPS permanent station in Tabriz. White profiles "a" and " $b$ " with $2 \mathrm{~km}$ sampling width are plotted in Fig. 5. (Color figure online)

calculated with respect to a zero deformation point in the study area. The zero deformation point for the relative LOS map was extracted by the following reasons: (1) it is selected somewhere in east of the Tabriz basin, away from the land subsidence patterns, (2) it is selected based on high coherence values in the produced inerferograms and (3) it is selected based on the previous InSAR and GPS velocity map of the region suggested by Rizza et al. (2013). The dark blue PSs are abundant at the north block of the North Tabriz Fault, associated with interseismic slip rate of the fault (Karimzadeh et al. 2013; Rizza et al. 2013). Two profiles with $2 \mathrm{~km}$ PS sampling width in the TB are drawn from north to south, perpendicular to the North Tabriz fault as a major tectonic feature of the study region. (1) Profile "a" which crosses from the first subsidence bowl in the north. (2) Profile "b" which crosses from the inner margin of the TB (Fig. 5). The effect of atmospheric phase delay could be large from several of $\mathrm{mm}$ to tens of $\mathrm{cm}$, comes from the temporal variation of the stratified troposphere (e.g., Hanssen 2001). Consequently the phase patterns typically mimic the topography. It means that in areas with high correlation between topography and InSAR, it is difficult to separate atmospheric and deformation signal, but in this study, the subsidence rates (gray points) are almost independent from the topography (redline) which is shown in Fig. 5. Absence of correlation between the mean PS subsidence rates and topography along the profiles demonstrates that atmospheric effects are too small. 

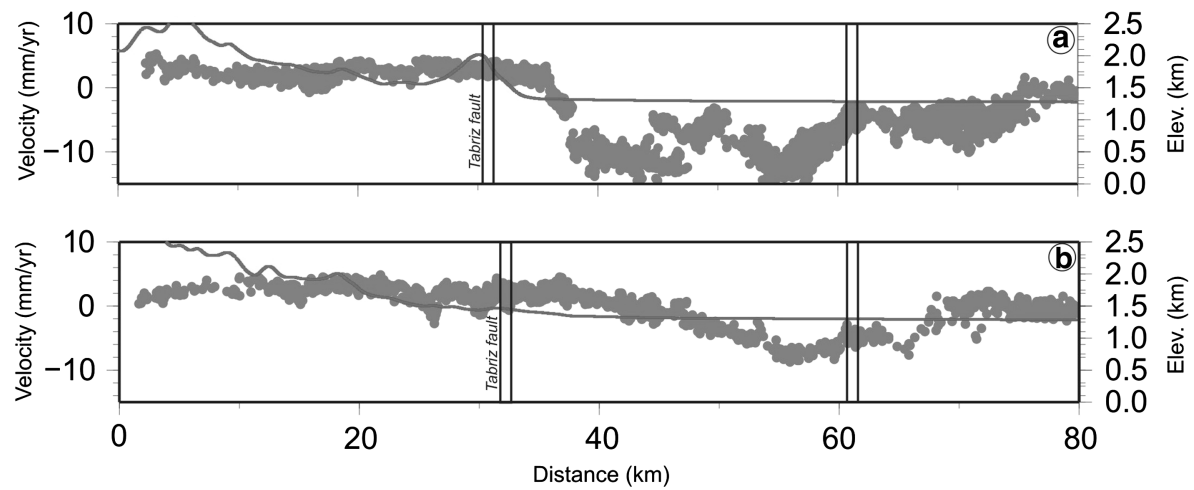

Fig. 5 PS and topography profiles showing subsidence rate and topographic variation in the TB (see the locations in Fig. 4). (Color figure online)
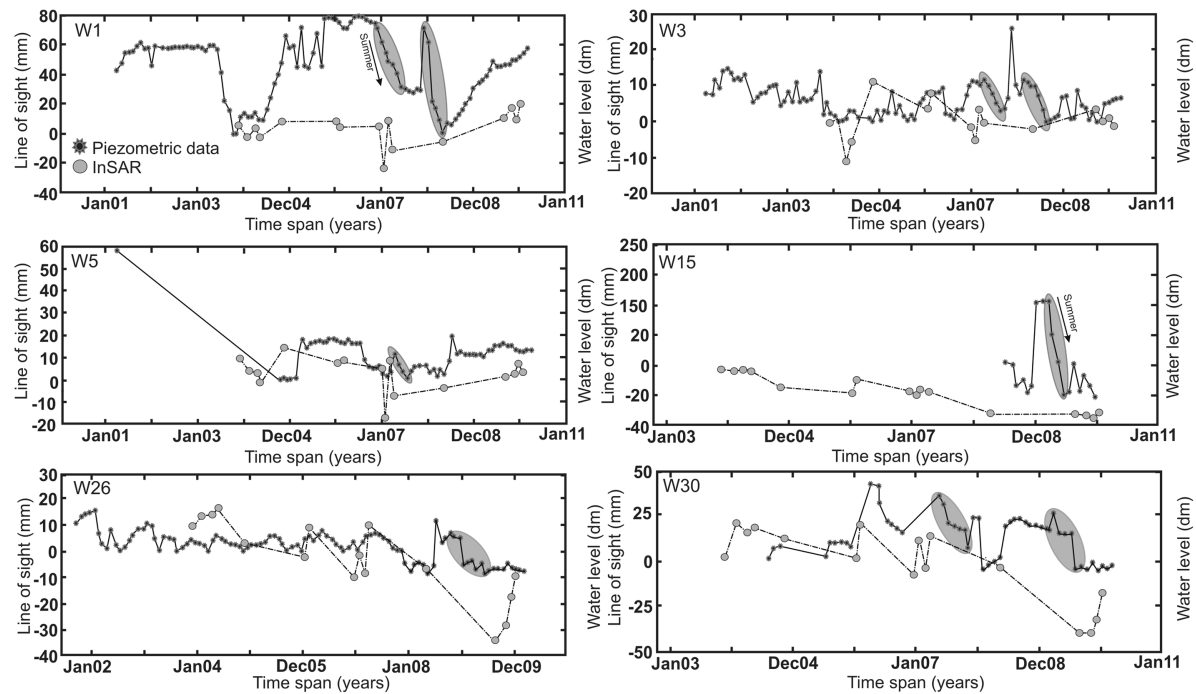

Fig. 6 Water level fluctuation and InSAR time series at the piezometric wells $(1,3,5,15,26$ and 30). InSAR results show at W1, W3 and W5 (sub-basin 2) seasonal deformation has been occurred but they do not show considerable subsidence between 2004 and 2010 while W15, W26 and W30 which are located in the sub-basin 1 (lesser water accumulation) have maximum ground subsidence between 2007 and 2009. Some seasonal changes are between 2007 and 2009 are shown by pink ellipsoids. (Color figure online)

The related piezometric data are collected from 2001 to 2010 monthly, but because of road constructions and some civil projects at the $\mathrm{TB}$, observations were stopped in some wells (e.g., W15). Piezometric measurements of the wells 15, 26 and 30 located in the subbasin 1 are showing the land subsidence in some epochs (Fig. 6). However some piezometric fluctuations do not confirm InSAR time series which means that subsidence is not only a function of water level fluctuations and needs more supplementary data and field observations or in other words, the InSAR time series by a few images in some epochs are not able to give us high correlation of water level and subsidence rate. For example 
between 2007 and 2009, decline of water level at the W30 is almost lower than the relevant InSAR time series. One reason could be by hydrogeological structures of the region (high permeability) which should be investigated in future works. It seems the correlation between land subsidence and change in groundwater level appears to be better defined in summer season (Fig. 6). InSAR time series also show that the cumulative subsidence for the epoch of 2004-2010 in the W26 and W30 is around $22 \mathrm{~mm}$ and $40 \mathrm{~mm}$ respectively, larger than the other boreholes.

\subsection{Storage coefficient}

Several studies have already suggested relationships between land subsidence and the properties of the aquifer system (e.g. Galloway et al. 1998; Kim et al. 2010; Lu and Danskin 2001; Nwankwor and Egboka 1992; Riley 1969) but in this study the knowledge of the aquifer cycle is lacking. Thus, a one dimensional model is applied. The model directly depends on subsidence/uplift amount to groundwater level variation by the storage coefficient $\left(S_{k}\right)$. This is a simple model considers that the compaction is uniaxial and vertical and it is useful when there is not geomechanical knowledge of the studied system. Then, the proposed model by Tomás et al. (2010) is followed:

$$
S_{k}=\frac{\Delta D}{\Delta h}
$$

where $\Delta D$ is the land subsidence associated to a $\Delta h$ piezometric level decrease. In order to determine $S_{k}$ values, a unique hydrological system at depth has been assumed corresponding to where groundwater is pumped, without alternated aquitards and aquifers. The piezometric levels of the classified wells located in the Fig. 3 are used. Six significant values for $S_{k}$ (Table 3 ) are obtained. These values are smaller than $2 \times 10^{-1}$ except the one obtained for borehole 30 for the period from 2004 to 2010 , which is at 0.4 . The average value of $S_{k}$ is at $7.7 \times 10^{-2}$. If we do not take into account the highest value from borehole 30 , the average $S_{k}$ value is at $1.2 \times 10^{-2}$. For the sub-basin 1 in the center of the subsidence patterns, W15 shows $2 \mathrm{~m}$ water level declining and $0 \mathrm{~mm}$ subsidence between 2008 and 2010 which means that the storage coefficient is zero. At the period between 2004 and 2010, W26 and W30 show 1.5 and $0.1 \mathrm{~m}$ water level declining, 22 and $40 \mathrm{~mm}$ subsidence, respectively. Also the yielded storage coefficient form W26 and W30 are 0.146 and 0.4

Table 3 Total subsidence/uplift, water level and storage coefficients $\left(S_{k}\right)$ at the excavated wells of TB

\begin{tabular}{llllll}
\hline ID & $\begin{array}{l}\text { Time } \\
\text { period (yr) }\end{array}$ & $\begin{array}{l}\text { Subsidence/ } \\
\text { uplift }(\mathrm{mm})\end{array}$ & $\begin{array}{l}\text { Mean 7-year } \\
\text { displacement } \\
\text { rate (mm/yr) }\end{array}$ & $\begin{array}{l}\text { Water } \\
\text { level (m) }\end{array}$ & $S_{k}$ \\
\hline $\begin{array}{l}\text { Sub-basin 1 } \\
\text { W15 }\end{array}$ & $2008-2010$ & 0 & & & 0 \\
W26 & $2004-2010$ & -22 & -5.7 & -2 & 0.146 \\
W30 & $2004-2010$ & -40 & -2.8 & -0.1 & 0.4 \\
Sub-basin 2 & & & -5.7 & & 0.0028 \\
W1 & $2004-2010$ & +14 & & +5 & 0 \\
W3 & $2004-2010$ & 0 & +2 & +0.6 & -0.0866 \\
W5 & $2005-2010$ & -11 & -1.5 & +1.27 & \\
\hline
\end{tabular}


respectively (see details in Table 3). Water decline in W26 and W30 is lower than W15 in the epoch of 2008-2010. One reason could be existence of an unknown fault between W26 and W30 (see Fig. 3) which confines water penetration to another layers (Anderssohn et al. 2008). However further investigation is needed about the below layers; another reason could be related with the large amount of the fine grained materials which have main roles in charging intervals (Haddadan and Zohrab 1994). For wells of the sub-basin 2 located in the western margin of the subsidence pattern minor uplift or subsidence have been observed (Fig. 6). Declining trend associated with the InSAR time series of W15 has been accelerated between 2006 and 2009 while for W26 and W30, it happened from 2007 to 2009. At the end of 2009 and early 2010 minor uplift probably comes from seasonal recharges. If the subsidence continues with the same acceleartion of 2007-2009 epoch, the subsidence patterns would be expanded to the outer margins of the TB in near future.

\subsection{GPS vs InSAR}

Information of geodetic measurements near of the subsidence region are lacking except one permanent GPS station in the Tabriz city which belongs to National Cartographic Center (NCC). It is established on a pillar extending deep into the ground to provide stability (Djamour et al. 2011). On the other hand, number of PSs is sparse in some areas. Therefore, they were not reliable for comparison with the GPS continuous station (TABZ). To resolve this inconsistency, the InSAR results are refined, and the uncertainties in gap areas must be reduced for a flawless comparison between GPS and InSAR time series. The Kriging interpolation is a powerful statistical method in soil and earth sciences which allows us to convert "modality" of a dataset from discrete points into a grid data. In this study, a simple Kriging method to predict the unknown PS value on the surface is used. The unknown PS value at coordinates $38^{\circ} 03^{\prime} 21^{\prime \prime} \mathrm{N}$ and $46^{\circ} 20^{\prime} 34^{\prime \prime} \mathrm{E}$ (location of TABZ GPS station) can be calculated with the following general equation:

$$
P S\left(\text { Lon }_{i}, \text { Lat }_{j}\right)=\sum_{\alpha=1}^{n} W_{i j \alpha} \times P S_{\alpha}
$$

where $n$ is the number of known values; $P S_{\alpha} . W_{i j \alpha}$ is a set of weight factors for known $P S$.

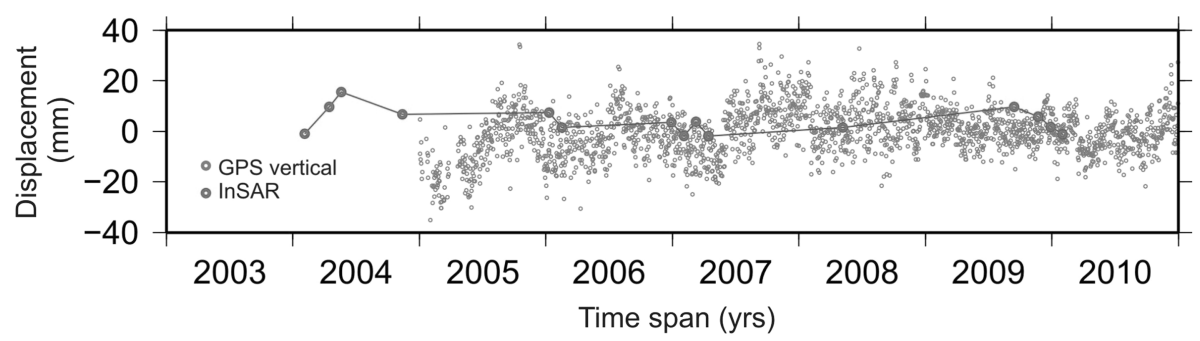

Fig. 7 Comparison of InSAR and GPS (converted to LOS rate) time series in the Tabriz station (TABZ) 
The weight factors are calculated by finding the semi-variogram values for all distances between input points and the semi-variogram values for all distances between an unknown $P S$ and all input points; a set of simultaneous equations must then be solved. Points closer to an unknown $P S$ take greater weight, while those farther away bear a lesser weight. The Kriging approach assumes that the distance of contributed points reflects a spatial correlation. Using this idea the gap area in the surface can be calculated. It fits a function to a specific number of points within a specific radius (here assumed to be $50 \mathrm{~m}$ ) to determine a reliable output value for the precise location of the TABZ station. The comparison confirms that land subsidence has not been entered into the urban areas (Fig. 7).

\section{Summary and conclusions}

Sixteen interferograms are produced from a pool of 17 ASAR images (with an acceptable threshold of coherence over 0.3) due to their small baselines shorter than $400 \mathrm{~m}$. The results of the InSAR analysis show that the maximum land subsidence is occurred in the well $30(\sim 40 \mathrm{~mm})$ at the center of the subsidence pattern which was growing between 2004 and 2009. The water level measurements and InSAR results are plotted in order to show the relationship between land subsidence, seasonal recharge and amount of water removal, but lack of enough geodetic observations (i.e. GPS or even precise leveling) in the study area restricts extensive interpretation of large-scale deformations. Only one thing, the subsidence rate was accelerated in W15, W26 and W30 (sub-basin 1) between 2007 and 2009 according to InSAR time series. With respect to the country's climate, seasonal water fluctuations (water recharge and discharge) are relatively correlated with seasonal climate condition of the above-mentioned wells (W15, W26 and W30). A few examples with drastic slope between 2007 and 2009 are shown in Fig. 6 by pink ellipsoids. Even, in some cases before 2007, you can see water level declines toward summer. For example in the W26 water level declines periodically every summer, but these trends have more acceleration after 2007 when the land subsidence accelerates as well. In the W1 and W3, in both summers 2007 and 2008, water level goes down because of extra agricultural activities and lack of rain precipitation. After that, because these wells are located in subbasin 2, naturally they receive larger amount of water with the onset of snow season then the water level goes up. It must be noted that unit-scale on Y-axis is different between water level and InSAR observations, thus visual comparison of these two kinds of observation does not sound reasonable.

The closest permanent GPS station (TABZ) shows good agreement with InSAR time series between 2005 and 2010, but the lack of geodetic measurements in the Tabriz basin (e.g. leveling/GPS data) is an obstacle for precise characterization of the subsidence patterns in the region. Mapping of subsurface layers in the region together with spatiotemporal data from the above-mentioned geodetic tools would be vital to gain a better understanding of the relations between hydrological parameters and land subsidence in the future. The results of this paper could be a "call for action" to develop new geodetic stations in the Tabriz basin and design new water resource models before the region falls victim of intensive agricultural activities and anthropogenic changes like Mashhad valley in NE Iran.

Acknowledgments European Space Agency (ESA) has provided Envisat ASAR data for Tabriz region through the Category-1 research proposal \# 8094. Most figures were generated using public license Generic 
Mapping Tools (GMT) software (Wessel and Smith 1995). Two anonymous reviewers are thanked for invaluable comments on earlier draft of the manuscript and suggesting substantial improvements.

\section{References}

Akbari V, Motagh M (2011) Improved ground subsidence monitoring using small baseline SAR interferograms and a weighted least squares inversion algorithm. Geosci Remote Sens Let IEEE 9:437-441

Akbarimehr M, Motagh M, Haghshenas-Haghighi M (2013) Slope stability assessment of the Sarcheshmeh landslide, Northeast Iran, investigated using InSAR and GPS observations. Remote Sens 5(8):36813700

Alipour S, Motagh M, Sharifi M, Walter T.R (2008) InSAR Time Series investigation of Land Subsidence due to Groundwater Overexploitation in Tehran, Iran. IEEE second workshop

Anderssohn J, Wetzel H-U, Walter TR, Motagh M, Djamour Y, Kaufmann H (2008) Land subsidence pattern controlled by old alpine basement faults in the Kashmar Valley, northeast Iran: results from InSAR and levelling. Geophys J Int 174:287-294

Bell JW, Amelung F, Ferretti A, Bianchi M, Novali F (2008) Permanent scatterer InSAR reveals seasonal and long-term aquifer-system response to groundwater pumping and artificial recharge. Water Resour Res 44:W02407. doi:10.1029/2007WR006152

Dehghani M, ValadanZoej MJ, Entezam I, Mansourian A, Saatchi S (2009) InSAR monitoring of progressive land subsidence in Neyshabour, Northeast Iran. Geophys J Int 178:47-56

Djamour Y, Vernant P, Nankali HR, Tavakoli F (2011) NW Iran-eastern Turkey present-day kinematics: results from the Iranian permanent GPS network. Earth Planet Sci Lett 307:27-34

Ferretti A, Prati C, Rocca F (2001) Permanent scatters in SAR interferometry. IEEE Trans Geosci Remote Sens 39(1):8-20

Food and Agriculture Organization of the United Nations (FAO) (2009) Groundwater management in Iran, report

Freemantle T, Muller J.P (2010) Monitoring ground surface displacement in the Three Gorges area: an investigation into DEM validation and the application of InSAR, ESA DRAGON2\#5343

Galloway DL, Hudnut KW, Ingebritsen SE, Phillips SP, Peltzer G, Rogez F, Rosen PA (1998) Detection of aquifer system compaction and land subsidence using interferometric synthetic aperture radar, Antelope Valley, Mojave Desert, California. Water Resour Res 34(10):2573-2585

Haddadan M, Zohrab E (1994) Hydrogeology map of Tabriz. Geol Surv Iran 1:50000

Hanssen RF (2001) Radar interferometry: data interpretation and error analysis. Kluwer Academic, Dordrecht

Hoffmann J, Zebker HA (2001) Seasonal subsidence and rebound in Las Vegas Valley, Nevada, observed by synthetic aperture radar interferometry. Water Resour Res 37(6):1551-1566

Hooper A, Spaans K, Bekaert D, Cuenca MC, Arıkan M, Oyen A (2010) StaMPS/MTI Manual. Delft University of Technology, Delft

Hu J, Li ZW, Ding XL, Zh JJ, Zhang L, Sun Q (2014) Resolving three-dimensional surface displacements from InSAR measurements: a review. Earth Sci Rev 133:1-17

Kampes B, Usai S (1999) Doris: the delft object-oriented radar interferometric software. In: Proceedings 2nd international symposium operationalization of remote sensing, http://citeseerx.ist.psu.edu/viewdoc/ summary?doi=10.1.1.46.1689

Karimzadeh S, Cakir Z, Osmanoğlu B, Schmalzle G, Miyajima M, Amiraslanzadeh R (2013) Interseismic strain accumulation across the North Tabriz fault (NWIran) deduced from InSAR timeseries. J Geodyn $66: 53-58$

Kim SW, Wdowinski S, Dixon TH, Amelung F, Kim JW, Won JS (2010) Measurements and predictions of subsidence induced by soil consolidation using persistent scatterer InSAR and a hyperbolic model. Geophys Res Lett 37:L05304

Lu Z, Danskin WR (2001) InSAR analysis of natural recharge to define structure of a ground-water basin, San Bernardino, California. Geophys Res Lett 28(13):2661-2664

Lubis AM, Sato T, Tomiyama N, Isezaki N, Yamanokuchi T (2011) Ground subsidence in SemarangIndonesia investigated by ALOS-PALSAR satellite SAR interferometry. J Asian Earth Sci 40: 1079-1088

Madani K (2014) Water management in Iran: what is causing the looming crisis? J Environ Stud Sci 4: 315-328

Moghaddam AA, Najib MA (2006) Hydrogeologic characteristics of the alluvial tuff aquifer of northern Sahand Mountain slopes, Tabriz. Iran Hydrogeol J 14:1319-1329 
Moghtased-Azar K, Mirzaei A, Nankali HR, Tavakoli F (2012) Investigation of correlation of the variations in land subsidence (detected by continuous GPS measurements) and methodological data in the surrounding areas of Lake Urmia. Nonlinear Process Geophys 19:675-683

Motagh M, Djamour Y, Walter TR, Wetzel H-U, Zschau J, Arabi S (2007) Land subsidence in Mashhad Valley, Northeast Iran: results from InSAR, levelling and GPS. Geophys J Int 168(2):518-526. doi:10. 1111/j.1365-246X.2006.03246.x

Motagh M, Walter T, Sharifi MA, Fielding E, Schenk A, Anderssohn J, Zschau J (2008) Land subsidence in Iran caused by widespread water reservoir overexploitation. Geophys Res Lett 35:L1640

Nwankwor GI, Egboka BCE (1992) Leakage properties of the multi-aquifer system underlying the greater Onitsha water scheme borehole field, Anambra State, Nigeria. Hydrol Sci J 37(6):557-566

Osmanoğlu B, Dixon TH, Wdowinski S, Canob EC, Jianga Y (2011) Mexico City subsidence observed with persistent scatterer InSAR. Int J Appl Earth Obs Geoinf 13:1-12. doi:10.1016/j.jag.2010.05.009

Razzaghmanesh M, Salemi T, Seraj M (2006) Ground water quality and quantity of Tabriz plain. In: National conference on irrigation and drainage network management (In Persian)

Rigo A, Béjar-Pizarro M, Martínez-Díaz J (2013) Monitoring of Guadalentín valley (southern Spain) through a fast SAR Interferometry method. J Appl Geophys 91:39-48

Riley FS (1969) Analysis of borehole extensometer data from Central California. Int Assoc Sci Hydrol Publ 89:423-431

Rizza M, Vernant P, Ritz JF, Peyret M, Nankali H, Nazari H, Djamour Y, Salamati R, Tavakoli F, Chery J, Mahan SA, Masson F (2013) Morphotectonic and geodetic evidence for a constant slip-rate over the last $45 \mathrm{kyr}$ along the Tabriz fault (Iran). Geophys J Int 193:1083-1094

Sedighi M, Nankali HR, Arabi S, Tavakoli F (2010) Subsidence detection in Salmas area using InSAR and geodetic techniques. Geospatial Eng J 1(4):25-33

Sousa J, Hooper A, Hanssen R, Luisa B, Antonio R (2011) Persistent Scatterer InSAR: a comparison of methodologies based on a model of temporal deformation versus spatial correlation selection criteria. Remote Sens Environ 115:2652-2663

Tomás R, Herrera G, Delgado J, Lopez-Sanchez JM, Mallorquí JJ, Mulas J (2010) A ground subsidence study based on DInSAR data: calibration of soil parameters and subsidence prediction in Murcia City (Spain). Eng Geol 111:19-30

Wessel P, Smith WHF (1995) New version of the generic mapping tools released. EOS Trans Am Geophys Union 76(33):329 